\title{
BMJ Open Long-term neuroprotective effect of erythropoietin on executive functions in very preterm children (EpoKids): protocol of a prospective follow- up study
}

\author{
Flavia Maria Wehrle, ${ }^{1,2,3}$ Ulrike Held, ${ }^{4}$ Ruth Tuura O'Gorman, ${ }^{2,5}$ Vera Disselhoff, ${ }^{1,2}$ \\ Barbara Schnider, ${ }^{1,2}$ Jean-Claude Fauchère, ${ }^{6}$ Petra Hüppi, ${ }^{7}$ Beatrice Latal, ${ }^{2,3}$ \\ Cornelia Franziska Hagmann ${ }^{1,2}$
}

To cite: Wehrle FM, Held U, 0'Gorman RT, et al. Longterm neuroprotective effect of erythropoietin on executive functions in very preterm children (EpoKids): protocol of a prospective follow-up study. BMJ Open 2018;8:e22157. doi:10.1136/ bmjopen-2018-022157

- Prepublication history for this paper is available online. To view these files, please visit the journal online (http://dx.doi. org/10.1136/bmjopen-2017022157).

Received 6 February 2018 Revised 13 February 2018 Accepted 14 February 2018

Check for updates

For numbered affiliations see end of article.

Correspondence to

Dr Cornelia Franziska Hagmann; cornelia.hagmann@kispi.uzh.ch

\section{ABSTRACT}

Introduction Premature infants are particularly vulnerable to brain injuries with associated cognitive and behavioural deficits. The worldwide first randomised interventional multicentre trial investigating the neuroprotective effects of erythropoietin (entitled 'Does erythropoietin improve outcome in very preterm infants?' (NCT00413946)) included 450 very preterm infants in Switzerland. MRI at term equivalent age showed less white matter (WM) injury in the erythropoietin group compared with the placebo group. Despite these promising imaging findings, neurodevelopmental outcome at 2 years showed no beneficial effect of early erythropoietin. One explanation could be that the assessment of more complex cognitive functions such as executive functions (EFs) is only possible at a later age. We hypothesise that due to improved WM development and fewer WM injuries, children born preterm treated with early erythropoietin will have better EF abilities at 7-12 years than those treated with placebo.

Methods and analysis 365 children who were included into the primary analysis of the original trial (NCT00413946) will be eligible in this prospective follow-up study at the age of 7-12 years. 185 children born at term will be control children. Primary outcome measures are EF abilities and processing speed, while secondary outcomes are academic performance, $I Q$, fine motor abilities and global brain connectivity. A comprehensive test battery will be applied to assess EFs. MRI will be performed to assess global brain connectivity. Cognitive scores and MRI measures will be compared between both groups using the Wilcoxon test. Propensity score matching will be used to balance gender, age, socioeconomic status and other potentially unbalanced variables between the children born preterm and the healthy control children.

Ethics and dissemination The cantonal ethical committee granted ethical approval for this study (KEK 2017-00521). Written consent will be obtained from the parents. Findings from this study will be disseminated via international and national conference presentations and publications in peer-reviewed journals.

\section{Strengths and limitations of this study}

- Long-term effects of early high-dose erythropoietin administration on executive function abilities and brain development will be investigated in children born very preterm.

- Long-term follow-up data on executive function abilities, processing speed and academic performance of a large cohort of very preterm children will be available through this study.

- Executive function abilities will be assessed comprehensively using standardised neuropsychological tests to measure core functions such as inhibition, cognitive flexibility, working memory and planning, and by investigating everyday life abilities as reported by the parents.

- Potential recruitment bias by the neurodevelopmental outcome of children born very preterm and by the socioeconomic status exists.

- Achieving the desired follow-up rate might prove challenging since the original randomised controlled trial was conducted between 2005 and 2012.

\section{INTRODUCTION}

Premature infants are particularly vulnerable to brain injury. As a consequence of perinatal brain injury, $5 \%-10 \%$ of survivors of premature birth develop cerebral palsy, and $40 \%-50 \%$ develop cognitive and behavioural deficits. ${ }^{12}$ A meta-analysis showed that children born very preterm manifest moderate to severe deficits in academic achievement, attention problems, internalising problems and poor executive functions. ${ }^{3}$ Executive functions refer to a family of top-down mental processes needed to attend to a task requiring concentration and attention. ${ }^{4}$ Three core executive functions have been described, namely, inhibition (the ability to suppress an automatic response), working memory (the 
ability to manipulate information in short-term memory) and cognitive flexibility (the ability to switch between different mindsets, creatively thinking 'outside the box'). ${ }^{5}$ Children born very preterm frequently perform worse in tests of inhibition, working memory and cognitive flexibility than age-matched term-born controls. ${ }^{367}$ Deficits across multiple executive function domains were also reported in adolescents ${ }^{89}$ and in adults born preterm. ${ }^{10-12}$ In addition to deficits in executive functions, processing speed has also been shown to be affected in adults born preterm. ${ }^{10}$ This is consistent with studies in children born preterm showing slower processing speed than term born children in infancy, ${ }^{13}{ }^{14}$ toddlerhood ${ }^{15}$ and middle childhood. $^{91617}$ These impairments are likely to influence academic success. Indeed, it has been reported in schoolaged children born very preterm that executive function deficits have a strong impact on learning skills ${ }^{9}$ and that processing speed and working memory abilities underlie academic attainment. ${ }^{1819}$

Associations between executive function deficits and cortical abnormalities have been reported in children and adults born very preterm. ${ }^{20-22}$ Structural alterations such as reduced grey and white matter volume accounted for $29 \%$ of the variance in executive functions in adolescents born very preterm at 12 years of age. ${ }^{23}$ Also, delayed cortical maturational trajectories and significant associations between the change in cortical thickness and executive function scores were observed in adolescents born very preterm. ${ }^{21}$ Similarly, processing speed appears to be related to neonatal brain injury in very preterm children. $^{24}$

The high incidence of neurodevelopmental impairments including executive function deficits in very preterm infants is reflected in the ongoing search for neuroprotective interventions that can prevent brain injury or enhance repair of the immature brain, with the ultimate goal of improving long-term motor and cognitive outcome.$^{25}$ However, to date, no such postnatal neuroprotective intervention has been implemented into clinical management of very preterm infants. A neuroprotective intervention ideally addresses both the prevention of brain injury and subsequent failure of normal brain development. ${ }^{26}$ Among several pharmacological candidates to prevent brain injury or to improve its development, erythropoietin has been shown to be one of the most promising neuroprotective agents. ${ }^{27}$ Erythropoietin may exert its neuroprotective role by preventing acute injury via inhibition of glutamate release, modulation of intracellular calcium metabolism, induction of neuronal antiapoptotic factors, reduction of inflammation, decrease of nitric oxide-mediated injury and direct antioxidant effects. ${ }^{28}{ }^{29}$ Furthermore, erythropoietin plays a role in developmental mechanisms, as it promotes proliferation and differentiation of preoligodendrocytes, and stimulates growth factors, such as vascular endothelial growth factor for increased angiogenesis, and brain-derived neurotrophic factor required for brain growth. ${ }^{28}$
In Switzerland, the first interventional trial in very preterm infants using high-dose erythropoietin as a potential neuroprotective agent was initiated in 2005. It was a randomised, double-blind placebo-controlled, prospective multicentre trial entitled 'Does erythropoietin improve outcome in very preterm infants?' (NCT00413946) and has included 450 very preterm infants born below 32 weeks of gestation between 2005 and 2012. ${ }^{30}$ Conventional MRI assessed in a subgroup of these infants showed that erythropoietin treatment was associated with a reduced risk of periventricular white matter injury, grey matter injury, white matter signal abnormalities and periventricular white matter volume loss, with a number needed to treat of seven preterm infants. ${ }^{31}$ Using tract-based spatial statistics of diffusion tensor imaging data, it was also shown that early highdose erythropoietin improved white matter development at term equivalent age in these very preterm infants. ${ }^{32}$ Importantly, improvement of white matter development was seen globally and was consistent with findings from the conventional MRI analysis. ${ }^{31}$ At 2 years of age, neurodevelopmental outcome data were available for 365 children $(81 \%)$. The mean mental and motor developmental indices as assessed by the Bayley Scales of Infant and Toddler Development-II were similar in both the erythropoietin and the placebo group. ${ }^{30}$ In light of the positive effects of erythropoietin on brain development, the question arises why these effects did not translate into improved neurodevelopmental outcome at 2 years of age. Two possible explanations are that, first, the sample size might have been too small. This would be in line with the findings of a recent meta-analysis, comprising 1113 infants of four randomised controlled studies, showing that prophylactic erythropoietin improved the cognitive development at 18-24 months. ${ }^{33}$ Second, merely developmental milestones can be measured at this young age while more complex cognitive functions such as executive functions are only developing, ${ }^{7}$ and hence the 2-year outcome might be used as a proof for safety of neuroprotective agents rather than their efficacy. ${ }^{34}$ We therefore speculate that in our cohort of infants, early high-dose erythropoietin may produce benefits for cognitive development that become apparent only at a later age once higher-order cognitive functions develop and potential deficits may become evident. We hypothesise that the improved white matter development and the reduced rate of white matter injuries will be reflected in better executive functions and in improved processing speed at school age; hence, that early high-dose erythropoietin administration after birth will lead to improved executive functions and processing speed at school age in very preterm children.

\section{HYPOTHESES AND AIMS OF THIS STUDY}

The main aim of this project is to examine whether early administration of high-dose erythropoietin in very preterm infants has long-term beneficial effects on 
executive functions, processing speed and global brain connectivity.

1. Very preterm children treated with early high-dose erythropoietin will have better executive function abilities and faster processing speed than those treated with placebo at the age of 7-12 years.

2. Global brain network connectivity is better in the children who were treated with early high-dose erythropoietin than in those treated with placebo.

3 . There is a continuum in executive function and academic performance within term born children, children born very preterm treated with high-dose erythropoietin and children born very preterm allocated to placebo.

4. Improved longitudinal brain development between term equivalent age and $7-12$ years $(n=165)$ can be shown in those children who were treated with early high-dose erythropoietin compared with those treated with placebo.

\section{METHODS AND ANALYSIS \\ Study participants}

Very preterm children who participated in the trial entitled 'Does erythropoietin improve outcome in very preterm infants?' (NCT00413946) will be recruited at the age of 7-12 years. A total of 450 infants were enrolled and randomised (mean (range) gestational age, 29.0 (26.0-30.9) weeks; 264 (59\%) female; mean (range) birth weight, 1210 (490-2290) g). Among them, 230 were allocated to the erythropoietin and 220 to the placebo group. Two infants in the erythropoietin group were excluded due to diagnosis of syndromes, which affect neurodevelopmental outcome $(n=448)$. In the erythropoietin and placebo group, 57 infants received erythropoietin either in another dose as allocated or received supplemental erythropoietin and were therefore excluded. Further, 63 infants were excluded from the primary analysis (death or drop out), leaving 365 infants who were included into the primary analysis and therefore eligible for this study: 191 infants in the erythropoietin and 174 infants in the placebo group. A database of the erythropoietin trial including perinatal, socioeconomic and follow-up assessment data at 2 and 5 years of age has been established. Recruitment of the very preterm children will be done with an invitation letter sent by post and thereafter by telephone contact. In addition, 185 children born at term will be recruited as friends/siblings/peers of the preterm children or by advertisement through social media (www. epokids.ch) and at schools.

\section{Primary and secondary outcome}

The primary outcome measures of this study are executive functions and processing speed. The secondary outcome measures include academic performance, intelligence, fine motor abilities, brain development (global brain connectivity, network characteristics, brain volumes and biochemical profiles) assessed by MRI as well as
Table 1 Executive function abilities and processing speed

\begin{tabular}{|c|c|}
\hline Assessed abilities & Applied assessment tools \\
\hline $\begin{array}{l}\text { Inhibition and } \\
\text { interference }\end{array}$ & $\begin{array}{l}\text { Stop-Signal Task (stop-signal reaction } \\
\text { time) } \\
\text { Color Word Interference Task (D-KEFS) }\end{array}$ \\
\hline Working memory & $\begin{array}{l}\text { Digit Span forward/backward (WISC- } \\
\text { IV) } \\
\text { Corsi Block Tapping Test } \\
\text { TAP Working Memory (TAP 2.3) }\end{array}$ \\
\hline Cognitive flexibility & $\begin{array}{l}\text { Trail Making Task (D-KEFS) } \\
\text { TAP Flexibility (TAP 2.3) }\end{array}$ \\
\hline Planning & Tower Task (D-KEFS) \\
\hline Fluency & $\begin{array}{l}\text { Verbal Fluency (RWT) } \\
\text { Design Fluency (D-KEFS) }\end{array}$ \\
\hline $\begin{array}{l}\text { Executive functions } \\
\text { in everyday life }\end{array}$ & Parent rating (BRIEF questionnaire) \\
\hline Processing speed & $\begin{array}{l}\text { Coding, Symbol Search (both WISC- } \\
\text { IV) } \\
\text { Stop-Signal Task (mean reaction time } \\
\text { of correct go trials) }\end{array}$ \\
\hline
\end{tabular}

Study-specific test battery to assess executive functions and processing speed.

BRIEF, Behaviour Rating Inventory of Executive Functions;

D-KEFS, Delis-Kaplan Executive Function System; RWT, Regensburger Verbal Fluency Test (Regensburger

Wortflüssigkeitstest); TAP, Test Battery for Attention Testing

(Testbatterie zur Aufmerksamkeitsprüfung); WISC-IV,

Wechsler Intelligence Scale for Children Fourth Edition.

behavioural problems, quality of life and variables of the family environment. The comparison of cognitive outcome measures and brain development between children born at term and children born very preterm is also a secondary outcome measure.

Primary outcome measures: executive functions and processing speed

Standardised neuropsychological tasks will be used to capture key aspects of executive functions, such as inhibition and interference, working memory, cognitive flexibility, planning, fluency and processing speed (table 1). Specifically, the stop-signal paradigm is a computerised tool for the investigation of response inhibition. ${ }^{35}$ For this study, the task will be implemented in MATLAB (MathWorks) using the Psychtoolbox extensions. ${ }^{36}$ All settings will be adopted from a previous study with very preterm children of a similar age. ${ }^{37}$ In addition to the different measures of response inhibition, the mean reaction time of all correct go-trials will be used to assess processing speed. The 'Test Battery for Attention Testing' (Testbatterie zur Aufmerksamkeitsprüfung ${ }^{38}$ ) consists of a set of computerised tests to selectively assess specific aspects of attentional processes. In this study, the flexibility and working memory subtests will be administered. The 'Delis-Kaplan Executive Function System ' ${ }^{39}$ is a test battery designed exclusively for the assessment of executive functions, within both verbal and spatial modalities. For this 
study, the Color-Word-Interference Task (inhibition), the Trail Making Task (cognitive flexibility), the Tower Task (visual-spatial planning) and the Design Fluency Test (fluency in generating visual patterns) will be used. The 'Regensburger Verbal Fluency Test' (Regensburger Wortflüssigkeitstest ${ }^{40}$ ) is a German language verbal fluency test, and phonetic and semantic subtests will be used for this study. The "Corsi Block Tapping-Test'" is a well-validated tool often applied in clinical practice and experimental research. The forward and backward conditions will be used to assess visual-spatial short-term and working memory, respectively. The following subtests of the 'Wechsler Intelligence Scale for Children, Fourth Edition' (WISC-IV, German version ${ }^{42}$ ) will be used: the Digit Span subtest will be used to assess verbal shortterm, and working memory and the Symbol Search and Coding subtests will be used to assess processing speed. The 'Behaviour Rating Inventory of Executive Functions' $\left(\mathrm{BRIEF}^{43}\right)$ is a questionnaire designed to gather information about an individual's use of executive function skills in daily life (at home and in school). Parents will complete this questionnaire.

\section{Secondary outcome measures}

Intelligence, fine motor abilities and academic performance

Intelligence will be estimated with four subtests of the WISC-IV $^{42}$ : Block Design, Similarities, Digit Span and Coding. This subtest combination has been shown to correlate highly with the full version $(r>0.90) .{ }^{44}$ To assess fine motor abilities, the Pegboard and Sequential Finger Movements subtests of the Zurich Neuromotor Assessment ${ }^{45}$ will be used. Due to the lack of a comprehensive test battery to assess academic abilities appropriate for the Swiss school system (such as for example the Wechsler Individual Achievement Test-II ${ }^{46}$ ), in this study, subtests of different validated instruments will be applied to assess math, reading and spelling skills: mathematical abilities will be tested with the Subtraction and Completion subtests of the 'Heidelberger Computing Test' (Heidelberger Rechentest) ${ }^{47}$ and the Applied Math subtest of the 'Adaptive Intelligence Diagnostic Tool', Third Edition (Adaptives Intelligenzdiagnostikum (AID-3)). ${ }^{48}$ Reading skills will be tested with the 1-min Reading Fluency subtest of the 'Salzburger Reading and Writing Test-II' (Salzburger Lese-/ Rechtschreibtest-II $)^{49}$ and the Text Comprehension subtest of the 'Salzburger Reading Screening' (Salzburger Lesescreening ${ }^{50}$ ). Spelling skills will be tested with the Spelling subtest of the 'Hamburger Writing Test' (Hamburger Schreibprobe ${ }^{51}$ ).

This test battery will be divided into two sessions: the first testing session will be done in the morning (approximately 2 hours) and the second half (approximately 1.5-2 hours) after a lunch break, followed by the MRI at the end of the day. The executive function tests and the tests to assess school skills will be undertaken in a randomised order to avoid fatigue effects.

\section{Questionnaires}

In addition to collecting cognitive and neuroimaging data from the participants, they will also complete two questionnaires to report on their quality of life and their relationship with their parents. The parents will be asked to complete a set of questionnaires to provide detailed information on aspects of their children's behaviour and quality of life and on their own health and well-being, their relationship with their child and various aspects of the family situation. Table 2 provides an overview of the applied questionnaires.

\section{Magnetic resonance imaging}

Cerebral MRI will be performed on a 3T GE MR750 scanner. Hearing protection will be provided with earplugs and headsets. The heart and respiratory rate will be monitored continuously. Image analysis will focus on group differences in the global network connectivity, topology and brain development. For this purpose, diffusion tensor imaging will be performed $(\mathrm{TE} / \mathrm{TR}=77 / 6500 \mathrm{~ms}, 35$ gradient sampling directions, $4 \mathrm{~B} 0$ images, field of view (FOV): $27.8 \mathrm{~cm}$, acquisition matrix: $96 \times 96)$. Furthermore, for volumetric analysis 3D T1 SPGR $(\mathrm{TE} / \mathrm{TR}=5 / 11 \mathrm{~ms}$, inversion time $(\mathrm{TI})=600 \mathrm{~ms}$, flip angle: $8^{\circ}, \mathrm{FOV}=25.6 \mathrm{~cm}$, reconstruction matrix: $256 \times 256$, 158 slices/slab) and 3D T2 CUBE (TE/TR $=98 / 2800 \mathrm{~ms}$, FOV $=256 \mathrm{~cm}$, matrix: $256 \times 256)$ sequences will be acquired. Resting-state functional MRI (TE/TR=32/1925 ms, flip angle $=74^{\circ}, \mathrm{FOV}=27.8 \mathrm{~cm}$, matrix $=64 \times 64$ ) will be acquired for analysing the functional connectivity between the groups. Magnetic resonance spectroscopy (TE/TR 35/3000 ms) will be acquired with voxels placed in basal ganglia/thalami and frontal white matter, respectively, to look at group differences in the biochemical profile. Furthermore, T2 relaxometry will be performed using a dual echo $\mathrm{PD} / \mathrm{T} 2 \mathrm{FSE}$ sequence $\left(\mathrm{TE}_{1} /\right.$ $\mathrm{TE}_{2} / \mathrm{TR}=30 / 118 / 7000 \mathrm{~ms}$, echo train length $=16, \mathrm{FOV}=27.8$, matrix $=412 \times 224$ (interpolated to $512 \times 512$ ) ) in order to look at group differences in T2 times in the grey and white matter. Longitudinal brain growth can be analysed in the subgroup of infants in which imaging was acquired at term equivalent age $(n=165) .^{31}$

\section{Comparison of cognitive measures and global brain connectivity} between children born at term and children born very preterm

Cognitive scores and measures of global brain network connectivity will be compared between the children born very preterm and those born at term to test whether there is a continuum in executive function performance and connectivity within term born children, children born very preterm treated with early high-dose erythropoietin and children born very preterm treated with placebo (see the Statistics section).

\section{Study design and power calculation}

Study design

This is a prospective follow-up project of the randomised erythropoietin trial NCT00413946. Recruitment process: 450 very preterm infants were randomised into the erythropoietin trial between 2005 and 2012. Of these, the 365 children 
Table 2 List of applied questionnaires

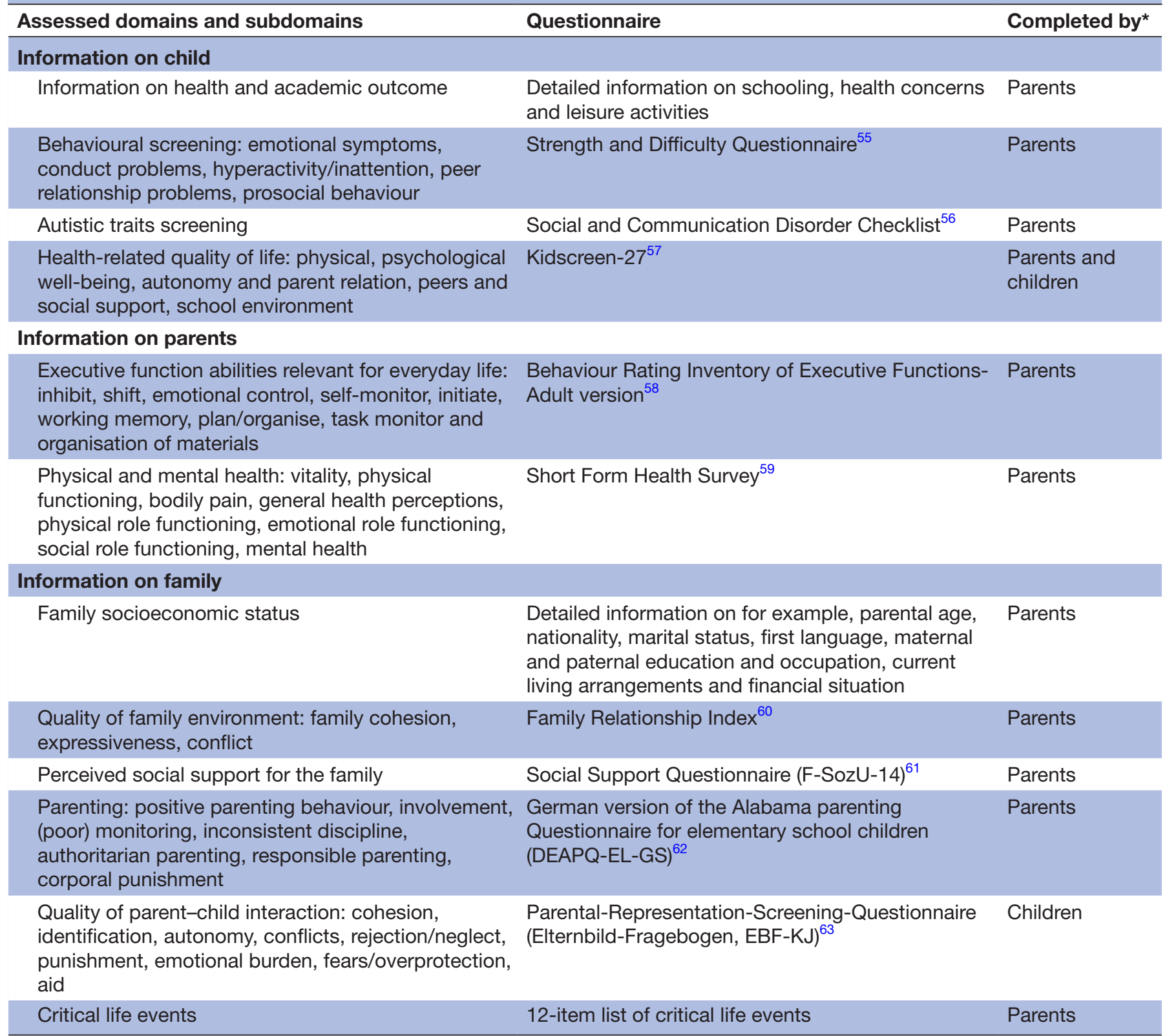

${ }^{*}$ Questionnaires are completed by at least one parent.

who were included into the primary analysis are eligible and will be contacted for this follow-up study. These children will be between 7 and 12 years old during the project time and are, hence, eligible for this study.

Power calculation: The primary outcome of this study will be assessed by the executive function tasks described above. Based on the literature, we expect a minimal effect size of 0.36 (since effect sizes for executive outcome measures range from 0.36 for working memory, 0.49 for cognitive flexibility and 0.57 for verbal fluency ${ }^{3}$ when comparing very preterm to term-born children). Considering the smallest effect size of 0.36 , a minimal sample size of 123 children/participants per group is required, assuming a two-sided alpha error of 0.05 and a power (1-beta) of 0.8 . To compensate for dropouts and considering that the effect size between preterm groups (erythropoietin vs placebo) might be smaller than between preterm participants and their term-born peers, we will add $20 \%$ to each group, targeting at least 148 children/participants per group, in total 296 children. There might be some imbalance in the distribution of gestational age, socioeconomic status or gender in the children willing to participate in this follow-up study between treatment groups. These imbalances will be taken into account in the analysis.

\section{Statistics}

Descriptive statistics include mean and SD or median and IQR for the continuous or ordinally scaled variables. Numbers and percentages of total will be reported for the categorical variables. Unpaired Wilcoxon tests or 
t-tests for ordinally scaled or continuous variables and $\chi^{2}$ or Fisher's exact test for dichotomous outcomes will be used. Linear regression models will be used to examine differences between the groups in executive function abilities. The independent variable in all regression models will be group status (erythropoietin vs placebo) and potentially other variables such as gender, gestational age and socioeconomic status. $\mathrm{P}$ values $<0.05$ will be considered statistically significant. Brain network features will be analysed using graph theory measures, characterising network structure and function. ${ }^{52} 53$ Network description will include measures of topological organisation (modularity, small-world and rich-club indices), integration and segregation. Cognitive scores and measures of global brain network connectivity and topography will be compared between the erythropoietin and placebo group using the Wilcoxon test. The statistical programming language $\mathrm{R}^{54}$ for Windows will be used for all analyses.

In a secondary analysis, the 185 term-born control children, primarily recruited for the evaluation in this study, will be compared with the children born very preterm included in the erythropoietin trial. Propensity score matching will be used to balance gender, age, socioeconomic status and other potentially unbalanced variables between the children born very preterm and the termborn control children. The aim of this approach is to balance other factors, enabling the quantification of the effects of being born very preterm, and within subgroups of children with or without erythropoietin.

\section{ETHICS AND DISSEMINATION}

Written informed consent will be obtained from the parents. Data handling, record keeping and archiving will be done according the guidelines given by the ethical committee. The results of this study will be published in peer-reviewed journals, and the findings will be presented at national and international conferences for widespread dissemination of the results.

\section{Author affiliations}

${ }^{1}$ Department of Neonatology and Pediatric Intensive Care, University Children's Hospital Zurich, Zurich, Switzerland

${ }^{2}$ Children's Research Center, University Children's Hospital Zurich, Zurich,

Switzerland

${ }^{3}$ Child Development Center, University Children's Hospital Zurich, Zurich, Switzerland

${ }^{4}$ Department Biostatistics, Epidemiology, Biostatistics and Prevention Institute, University of Zurich, Zurich, Switzerland

${ }^{5} \mathrm{MR}$ Research Centre, University Children's Hospital Zurich, Zurich, Switzerland ${ }^{6}$ Department of Neonatology, University Hospital Zurich and University of Zurich, Zurich, Switzerland

${ }^{7}$ Division of Child Development and Growth, Department of Paediatrics, Geneva University, Geneva, Switzerland

Contributors CFH, FW, RTOG, UH and BL were involved in the study design. FW, $\mathrm{BS}$, VD and CFH were responsible for conceiving ethical approval. CFH, FW, RTOG and UH wrote the first draft of the manuscript. CFH, FW, RTOG, UH, BL, PH, J-CF, VD and BS commented and critically reviewed drafts of the paper.
Funding This project is supported by the Swiss National Science Foundation (grant number 320030_169733), the Gottfried and Julia Bangerter-Rhyner Foundation, the Hartmann Müller Foundation and the Uniscientia Foundation.

Competing interests None declared.

Patient consent Parental/guardian consent obtained.

Ethics approval The cantonal ethical committee of Zurich, Switzerland, granted ethical approval for this study in May 2017 (KEK 2017-00521).

Provenance and peer review Not commissioned; peer reviewed for ethical and funding approval prior to submission.

Open Access This is an Open Access article distributed in accordance with the Creative Commons Attribution Non Commercial (CC BY-NC 4.0) license, which permits others to distribute, remix, adapt, build upon this work non-commercially, and license their derivative works on different terms, provided the original work is properly cited and the use is non-commercial. See: http://creativecommons.org/ licenses/by-nc/4.0/

(c) Article author(s) (or their employer(s) unless otherwise stated in the text of the article) 2018. All rights reserved. No commercial use is permitted unless otherwise expressly granted.

\section{REFERENCES}

1. Lacey DJ, Topper WH, Buckwald S, et al. Preterm very-low-birthweight neonates: relationship of EEG to intracranial hemorrhage, perinatal complications, and developmental outcome. Neurology 1986;36:1084-7.

2. Saigal S, Doyle LW. An overview of mortality and sequelae of preterm birth from infancy to adulthood. Lancet 2008;371:261-9.

3. Aarnoudse-Moens CS, Weisglas-Kuperus N, van Goudoever JB, et al. Meta-analysis of neurobehavioral outcomes in very preterm and/ or very low birth weight children. Pediatrics 2009;124:717-28.

4. Miller P, Brody CD, Romo R, et al. A recurrent network model of somatosensory parametric working memory in the prefrontal cortex. Cereb Cortex 2003;13:1208-18.

5. Diamond A. Executive functions. Annu Rev Psychol 2013;64:135-68.

6. Johnson S, Wolke D, Hennessy E, et al. Educational outcomes in extremely preterm children: neuropsychological correlates and predictors of attainment. Dev Neuropsychol 2011;36:74-95.

7. Anderson P. Assessment and development of executive function (EF) during childhood. Child Neuropsychol 2002;8:71-82.

8. Burnett AC, Scratch SE, Lee KJ, et al. Executive function in adolescents born $<1000 \mathrm{~g}$ or $<28$ weeks: a prospective cohort study. Pediatrics 2015;135:e826-34.

9. Farooqi A, Adamsson M, Serenius F, et al. Executive functioning and learning skills of adolescent children born at fewer than 26 weeks of gestation. PLoS One 2016;11:e0151819.

10. Nosarti C, Giouroukou E, Micali N, et al. Impaired executive functioning in young adults born very preterm. $J$ Int Neuropsychol Soc $2007 ; 13: 571-81$.

11. Pyhälä R, Lahti J, Heinonen K, et al. Neurocognitive abilities in young adults with very low birth weight. Neurology 2011;77:2052-60.

12. Eryigit Madzwamuse $\mathrm{S}$, Baumann $\mathrm{N}$, Jaekel J, et al. Neuro-cognitive performance of very preterm or very low birth weight adults at 26 years. J Child Psychol Psychiatry 2015;56:857-64.

13. Rose SA, Feldman JF, Jankowski JJ, et al. Pathways from prematurity and infant abilities to later cognition. Child Dev 2005;76:1172-84.

14. Rose SA, Feldman JF, Jankowski JJ, et al. A cognitive cascade in infancy: pathways from prematurity to later mental development. Intelligence 2008;36:367-78.

15. Rose SA, Feldman JF, Jankowski JJ. Information processing in toddlers: continuity from infancy and persistence of preterm deficits. Intelligence 2009;37:311-20.

16. Rose SA, Feldman JF. Memory and processing speed in preterm children at eleven years: a comparison with full-terms. Child Dev 1996;67:2005-21.

17. Mulder H, Pitchford NJ, Marlow N. Processing speed mediates executive function difficulties in very preterm children in middle childhood. J Int Neuropsychol Soc 2011;17:445-54.

18. Mulder H, Pitchford NJ, Marlow N. Processing speed and working memory underlie academic attainment in very preterm children. Arch Dis Child Fetal Neonatal Ed 2010;95:F267-72.

19. Rose SA, Feldman JF, Jankowski JJ. Modeling a cascade of effects: the role of speed and executive functioning in preterm/full-term differences in academic achievement. Dev Sci 2011;14:1161-75. 
20. Skranes J, Løhaugen GC, Evensen KA, et al. Entorhinal cortical thinning affects perceptual and cognitive functions in adolescents born preterm with very low birth weight (VLBW). Early Hum Dev 2012;88:103-9.

21. Nam KW, Castellanos N, Simmons A, et al. Alterations in cortical thickness development in preterm-born individuals: Implications for high-order cognitive functions. Neuroimage 2015;115:64-75.

22. Bjuland KJ, Løhaugen GC, Martinussen M, et al. Cortical thickness and cognition in very-low-birth-weight late teenagers. Early Hum Dev 2013;89:371-80.

23. Nosarti C, Giouroukou E, Healy E, et al. Grey and white matter distribution in very preterm adolescents mediates neurodevelopmental outcome. Brain 2008;131:205-17.

24. Murray AL, Scratch SE, Thompson DK, et al. Neonatal brain pathology predicts adverse attention and processing speed outcomes in very preterm and/or very low birth weight children. Neuropsychology 2014;28:552-62.

25. Gonzalez FF, Abel R, Almli CR, et al. Erythropoietin sustains cognitive function and brain volume after neonatal stroke. Dev Neurosci 2009;31:403-11.

26. Volpe JJ. Brain injury in premature infants: a complex amalgam of destructive and developmental disturbances. Lancet Neurol 2009;8:110-24.

27. Robertson NJ, Tan S, Groenendaal F, et al. Which neuroprotective agents are ready for bench to bedside translation in the newborn infant? J Pediatr 2012;160:544-52.

28. Juul S. Neuroprotective role of erythropoietin in neonates. J Matern Fetal Neonatal Med 2012;25(Suppl 4):105-7.

29. Shingo T, Sorokan ST, Shimazaki T, et al. Erythropoietin regulates the in vitro and in vivo production of neuronal progenitors by mammalian forebrain neural stem cells. $J$ Neurosci 2001;21:9733-43.

30. Natalucci G, Latal B, Koller B, et al. Effect of early prophylactic highdose recombinant human erythropoietin in very preterm infants on neurodevelopmental outcome at 2 years: a randomized clinical trial. JAMA 2016;315:2079-85.

31. Leuchter RH, Gui L, Poncet A, et al. Association between early administration of high-dose erythropoietin in preterm infants and brain MRI abnormality at term-equivalent age. JAMA 2014;312:817-24.

32. O'Gorman RL, Bucher HU, Held U, et al. Tract-based spatial statistics to assess the neuroprotective effect of early erythropoietin on white matter development in preterm infants. Brain 2015;138:388-97.

33. Fischer HS, Reibel NJ, Bührer $\mathrm{C}$, et al. Prophylactic early erythropoietin for neuroprotection in preterm infants: a meta-analysis. Pediatrics 2017;139:e20164317.

34. Marlow N. Is survival and neurodevelopmental impairment at 2 years of age the gold standard outcome for neonatal studies? Arch Dis Child Fetal Neonatal Ed 2015;100:F82-4.

35. Verbruggen F, Logan GD. Response inhibition in the stop-signal paradigm. Trends Cogn Sci 2008;12:418-24.

36. Brainard DH. The Psychophysics Toolbox. Spat Vis 1997;10:433-6.

37. Aarnoudse-Moens CS, Duivenvoorden HJ, Weisglas-Kuperus N, et al. The profile of executive function in very preterm children at 4 to 12 years. Dev Med Child Neurol 2012;54:247-53.

38. Zimmermann P, Fimm B. TAP; Testbatterie zur Aufmerksamkeitspruefung; Testbattery for Attentional Performance. Herzogenrath, Germany: Psytest, 1993.

39. Delis DC, Kaplan E, Kramer JH. Delis-Kaplan executive function system (D-KEFS): Psychological Corporation, 2001.

40. Aschenbrenner S, Tucha O, Lange KW. Regensburger Wortflüssigkeits-Test (RWT) [Regensburger verbal fluency test (RWT)] Göttingen: Hogrefe Verlag, 2000.
41. Kessels RP, van Zandvoort MJ, Postma A, et al. The corsi blocktapping task: standardization and normative data. Appl Neuropsychol 2000;7:252-8.

42. Petermann F, Petermann U. Hamburg-Wechsler Intelligenztest für Kinder-IV (HAWIK-IV) [Hamburg-Wechsler-Intelligence Test for children (HAWIK-IV)]. Bern: Huber, 2006.

43. Drechsler R, Steinhausen H-C. BRIEF: Verhaltensinventar zur Beurteilung exekutiver Funktionen. Manual. [BRIEF. A behavioral inventory to assess executive functions. Manual]. Bern, Switzerland: Huber, 2013.

44. Waldmann H-C. Kurzformen des HAWIK-IV: Statistische Bewertung in verschiedenen Anwendungsszenarien [German WISC-IV short forms: a scenario-based evaluation of statistical properties] Diagnostica 2008;54:202-10.

45. Largo RH. Zurich Neuromotor Assessment. Zurich: AWE Verlag, 2007

46. Wechsler D. Wechsler Individual Achievement Test-II. Antonio: TX: The Psychological Corporation, Harcourt Brace \& Co, 2001a.

47. Haffner J. Heidelberger Rechentest (HRT 1-4). Göttingen: Hofgrefe, 2005.

48. Kubinger KD, Holocher-Ertl S. Adaptives Intelligenz Diagnostikum 3. Göttingen: Beltz Test Gesellschaft, 2014.

49. Moll K, Landerl K. SLRT-Il: Lese-und Rechtschreibtest; Weiterentwicklung des Salzburger Lese-und Rechtschreibtests (SLRT): Huber, 2010.

50. Mayringer $\mathrm{H}$, Wimmer H. Salzburger Lese-Screening für die Klassenstufen 1-4. Bern, Switzerland: Huber, 2003.

51. May P. HSP 1-10. Hamburger Schreib-Probe. Göttingen: Hofgrefe, 2012.

52. Hagmann P, Grant PE, Fair DA. MR connectomics: a conceptual framework for studying the developing brain. Front Syst Neurosci 2012;6:43.

53. Fischi-Gómez E, Vasung L, Meskaldji DE, et al. Structural brain connectivity in school-age preterm infants provides evidence for impaired networks relevant for higher order cognitive skills and social cognition. Cereb Cortex 2015;25:2793-805.

54. R Development Core Team. R: a language and environment for statistical computing: R Foundation for Statistical Computing, 2008.

55. Goodman R. Psychometric properties of the strengths and difficulties questionnaire. J Am Acad Child Adolesc Psychiatry 2001;40:1337-45.

56. Skuse DH, Mandy WP, Scourfield J. Measuring autistic traits: heritability, reliability and validity of the Social and Communication Disorders Checklist. Br J Psychiatry 2005;187:568-72.

57. Ravens-Sieberer U, Auquier P, Erhart M, et al. The KIDSCREEN-27 quality of life measure for children and adolescents: psychometric results from a cross-cultural survey in 13 European countries. Qual Life Res 2007;16:1347-56.

58. Roth RM, Gioia GA. Behavior rating inventory of executive functionadult version. Lutz, FL: Psychological Assessment Resources, 2005.

59. Morfeld M, Kirchberger I, Bullinger M. SF-36 Fragebogen zum Gesundheitszustand: Deutsche Version des Short Form-36 Health Survey: Hogrefe, 2011.

60. RH M, BS M. Family environment scale manual: Consulting Psychologists Press, 1994.

61. Fydrich $\mathrm{T}$, et al. Fragebogen zur sozialen unterstützung (F-SozU): Normierung der Kurzform (K-14). Zeitschrift für Medizinische Psychologie 2009;18:43-8.

62. Reichle B, Franiek S. Erziehungsstil aus elternsicht: Deutsche erweiterte version des Alabama Parenting Questionnaire für Grundschulkinder (DEAPQ-EL-GS). Zeitschrift für Entwicklungspsychologie und Pädagogische Psychologie 2009;41:12-25

63. Titze K, Lehmkuhl U. Elternbildfragebogen für Kinder und Jugendliche: EBF-KJ; Manual: Hogrefe, 2010. 